\title{
Effect of Potassium and Valinomycin on Oxidative Phosphorylation in Intact Beef Heart Mitochondria and Submitochondrial Particles'
}

\author{
ELNORA II. SMITH ${ }^{2}$ AND ROBERT E. BEYER
}

\author{
Laboratory of Chemical Biology, Department of Zoology, The University of Michigan, \\ Ann Arbor, Michigan 48104
}

Received May 11, 1967; accepted June 27, 1967

\begin{abstract}
Beef heart mitochondria and submitochondrial particles have been used to measure parameters of oxidative phosphorylation with respert to varying concentrations of potassium and valinomycin. In the absence of valinomycin, intact mitochondria showed little response to potassium. The presence of valinomycin caused the following response of intact mitochondria to increasing potassium concentrations: lower $\Lambda D P / O$ ratio, lower rate of phosphorylation, no increase in state-3 respiration, higher respiration rate in state 4 , and lower respiratory control. In contrast, the $P / O$ ratio of submitochondrial particles was not altered significantly by increasing potassium concentrations in either the absence or the presence of valinomycin. It is suggested that potassium does not interact directly with the oxidative phosphorylation system but may compete with ATP syntbesis in intact beef heart mitochondria via an energyrequiring potassium transport system.
\end{abstract}

Although potassium has been shown to have an effect on mitochondrial oxidative phosphorylation, the site of action has not been demonstrated directly. Pressman and Lardy (1) have shown that potassium is essential for maximal rates of respiration and phosphorylation in rat liver mitochondria, and concluded that potassium participates in transphosphorylation reactions but does not directly influence oxidative reactions. These conclusions have been

- This research was partially supported by an NSF Lndergraduate Research Program Grant (GY-1027) to the Department of Zoology, The University of Michigan; a grant from the National Institute of Arthritis and Metabolic Diseases (NIH AM 10056); Institutional Grant 94 (The University of Michigan) from the National Science Foundation; American Cancer Society Institutional Grant (The liniversity of Michigan) IN-40G; and Institutional Research Grant 94 to The University of Michigan from the American Cancer Society.

${ }^{2}$ Recipient of an NSF Undergraduate Research Program Award. Present address: Department of Biology, Yale University, New Haven, Connecticut. challenged by Opit and Charnock (2), who were not able to demonstrate an effect of potassium on respiration, phosphorylation, $\mathrm{P} / \mathrm{O}$ ratios, or respiratory control in either fresh rat liver mitochondria or preparations previously incubated for 30 minutes at $30^{\circ}$. Nore recent work utilizing valinomycin, an antibiotic which facilitates the active transport of potassium through mitochondrial membranes $(3,4)$, has shown pronounced effects of potassium on oxidative phosphorylation (5). It has been suggested $(5,6)$ that the stimulatory effect of the combination of valinomycin and potassium is a result of the action of valinomycin on the mitochondrial ion transport system and the interaction of potassium with the energy transfer sequence leading to ATP synthesis.

The purpose of the present investigation was to determine the generality of previously reported effects of valinomycin and potassium by using mitochondria from beef heart instead of rat liver. In addition, the use of phosphorylating submitochondrial particles prepared from beef heart mitochondria was intended to permit a more 
direct examination of the effect of valinomycin and potassium on oxidative phosphorylation, since the oxidative phosphorylation system of such preparations appears to be in more intimate contact with the external medium.

The reported experiments demonstrate profound effects of potassium and valinomycin on intact beef heart mitochondria, while insignificant effects were observed with submitochondrial particles. These results would suggest that potassium does not play a critical role in the synthesis of ATP, but rather that potassium has a more indirect cffect on oxidative phosphorylation by utilizing the energy of ATP, or of a high-energy intermediate of oxidative phosphorylation, to earry out active transport of potassium across a mitochondrial membrane.

\section{MATERIALS AND METHODS}

Preparation of $\mathrm{HBHM.}{ }^{3} \mathrm{HBHM}$ were isolated from fresh bovine ventricular tissue essentially as described by Löw and Vallin (7) with the following modifications: potassium salts were not used, the preparation was not treated with nitrogen gas, homogenization was for 30 seconds instead of 1 minute, and the $\mathrm{pH}$ was maintained at 7.5 except during the separation of light from heavy beef heart mitochondria, at which time $\mathrm{pH} 7.8$ was employed. Homogenization was performed with a Willem's Polytron, model BEW. The mitochondrial pellet was washed twice and finally suspended to $30 \mathrm{mg}$ protcin $/ \mathrm{ml}$.

Preparation of ETPH $\left(\mathrm{Mg}^{++}, M n^{++}\right)$. Submitochondrial particles were prepared by the procedure of Hansen and Smith (8) as described by Beyer (9) for $\operatorname{ETPH}\left(\mathrm{Mg}^{++}, \mathrm{Mn}^{++}\right)$. In order to exclude potassium from our preparation, Tris salts were used. Mitochondria were fragmented with a Branson Sonifier, model S-75, $20 \mathrm{kc}, 15$ or 30 seconds duration, at a power output between 6 and $7 \mathrm{~A}$. Centrifugations were performed in a Beckman model $\mathrm{L}$ Ultracentrifuge with rotors of type 30 and type 50 .

Assay methods. Protein was delermined by a biuret procedure (10). Oxygen consumption was determined with a Clark electrode in a $3-\mathrm{ml}$ closed glass cuvette with rapid stirring at $25^{\circ}$. Oxygen consumption was recorded on a Sargent SR re-

${ }^{3}$ Abbreviations used. HBHM, heavy beef heart mitochondria; $\mathrm{ETPH}\left(\mathrm{Mg}^{++}, \mathrm{Mn}^{++}\right)$, electron transfer particle prepared from HBHM in the presence of $\mathbf{M g}^{++}$and $\mathrm{Mn}^{++}$. corder. $\mathrm{ADP} / \mathrm{O}$ and respiratory control ratios were calculated according to Chance and Williams (11). $\mathrm{P} / \mathrm{O}$ ratios catalyzed by $\mathrm{ETPH}\left(\mathrm{Mg}^{++}, \mathrm{Mn}^{++}\right)$ were determined by using ${ }^{32} \mathrm{P}_{\mathrm{i}}$ as tracer, as described by Beyer (9). Dissolved oxygen at $25^{\circ}$ was assumed to be $240 \mathrm{~mm}$. ADP was assayed spectrophotometrically with pyruvic kinase, lactic dehydrogenase, phosphoenolpyruvate, and NADH by following the decrease of absorbancy at $340 \mathrm{~m} \mu$ upon addition of ADP to the assay.

All chemicals were of analytical reagent grade or its equivalent and were obtained/commercially.

\section{RESULTS}

The presence of $\mathrm{KCl}$ in concentrations between 5 and $30 \mathrm{~mm}$ had little effect on the $\mathrm{ADP} / \mathrm{O}$ ratio of $\mathrm{HBHM}$ (Fig. 1). The slight stimulatory effect by potassium in the absence of valinomycin secn in Fig. 1 was not a consistent finding from preparation to preparation, and the data presented in Fig. 1 represent the largest increase noted in these experiments. In the presence of either 4 or $8 \mu \mathrm{g}$ of valinomycin per gram of mitochondrial protein, the decrease of the $\mathrm{ADP} / \mathrm{O}$ ratio was directly proportional to the increase in potassium concentration in the medium.

Incubation of liver mitochondria at $30^{\circ}$ or $38^{\circ}$ has been reported $(2,12)$ to lower the intramitochondrial potassium concentration by $60-85 \%$ in 20 minutes and, in addition, has been reported to increase the response of mitochondria to potassium in the absence of valinomycin (5). Therefore, in order to observe the effect of such a treatment on the response of HBHM to valinomycin and potassium, a portion of each HBHM preparation was incubated for 15 minutes at $37^{\circ}$, chilled, sedimented, and resuspended in fresh $0.25 \mathrm{~m}$ sucrose $-0.01 \mathrm{M}$ Tris, $\mathrm{pH}$ 7.5. The presence of potassium did not affect the ADP $/ O$ ratio of preincubated HBHM until a rather high concentration (30 mm) was employed which, in the case of the experiment reported in Table I, lowered the $\mathrm{ADP} / \mathrm{O}$ ratio significantly. It should be noted, however, that this particular extreme response to $30 \mathrm{~mm}$ potassium was not a consistent finding. The presence of $4 \mu \mathrm{g}$ of valinomycin per gram of mitochondrial protein resulted in an increase in the $\mathrm{ADP} / \mathrm{O}$ ratio at the low potassium concentration and a progressive decrease 


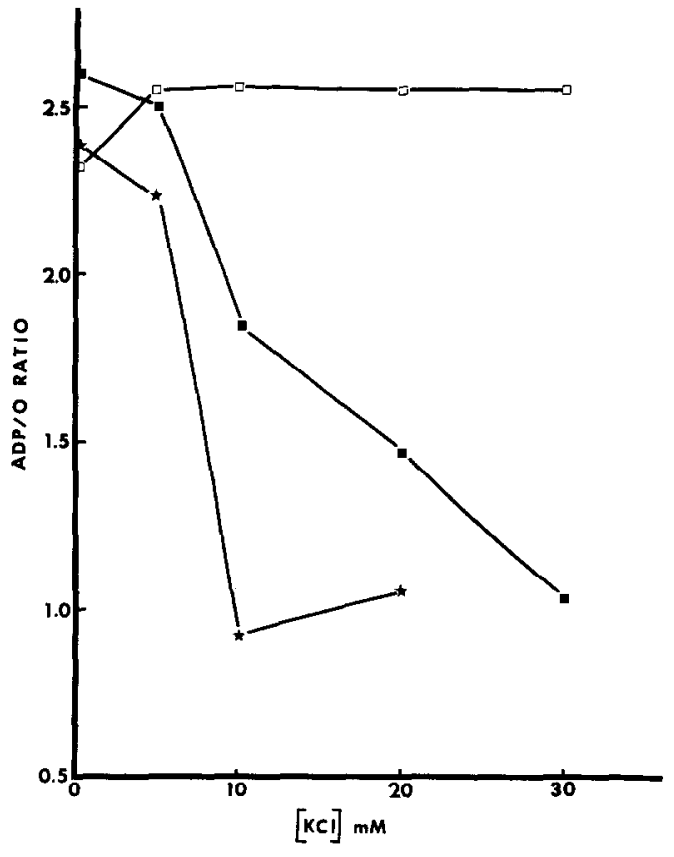

FIG. 1. The effect of valinomycin and potassium on $\mathrm{ADP} / \mathrm{O}$ ratios of $\mathrm{HBHM}$. Final concentrations of components: $0.3 \mathrm{M}$ mannitol, $5 \mathrm{mM} \mathrm{MgCl}$, $5 \mathrm{~mm}$ Tris-phosphate, $\mathrm{pH} 7.5$, and $1.5 \mathrm{mg}$ mitochondrial protein. The reactions were initiated by the addition of $20 \mu \mathrm{l}$ of $1 \mathrm{M}$ Tris-pyruvate0.1 м Tris-malule. The ADP/O ratios were determined twice for each incubation by the additions of $10 \mu \mathrm{l}$ of $42.2 \mathrm{~mm}$ Tris-ADP. Final volume, $3 \mathrm{ml}$. Temperature, $25^{\circ}$. No valinomycin ( $\left.\square\right), 4 \mu \mathrm{g}$ valinomycin/gm protein $(\square), 8 \mu \mathrm{g}$ valinomycin/gm protein $(\star)$.

with potassium concentrations between 10 and $30 \mathrm{~mm}$. As in the case of the data in Fig. 1, the increase at the low potassium concentration was the largest we observed in these experiments, and the phenomenon was not consistent. The decrease in the $\mathrm{ADP} / \mathrm{O}$ ratio reported in Table I for concentrations of potassium between 10 and $30 \mathrm{~mm}$ in the presence of 4 and $8 \mu \mathrm{g}$ of valinomycin per gram of mitochondrial protein was consistent in every experiment, and was frequently depressed below the levels reported for the experiment in Table I.

The respiratory control ratio is often employed as a criterion of the extent of coupling between the mitochondrial electron transfer chain and the energy conservationtransfer sequence. Therefore, the respira- tory control ratio of fresh HBHM prepared in the absence of potassium ions was determined, and the effect of added potassium in the absence and presence of valinomycin was noted (Fig. 2). In the absence of valino-

TABLE I

Effect of Potassium and Valinomycin on the ADP/O Ratio of Preincubated MitochondRIA

Experimental conditions were the same as those described in Fig. 1 except that the HBHM were preincubated at $37^{\circ}$ for 15 minutes. Pyruvate + malate were used as substrate.

\begin{tabular}{|c|c|c|c|}
\hline \multirow{2}{*}{$\mathrm{KCl}(\mathrm{mM})$} & \multicolumn{3}{|c|}{$\Lambda \mathrm{DP} / \mathrm{O}$} \\
\hline & $\begin{array}{c}\text { No } \\
\text { valinomycin }\end{array}$ & $\begin{array}{l}4 \mu \mathrm{g} \text { valinomy- } \\
\text { cin/gm protein }\end{array}$ & $\begin{array}{l}8 \mu \mathrm{g} \text { valinomy- } \\
\text { cin/gm protein }\end{array}$ \\
\hline 0 & 2.21 & 2.13 & 2.10 \\
\hline 5 & 2.13 & 2.55 & 2.13 \\
\hline 10 & 2.17 & 2.11 & 2.03 \\
\hline 20 & 2.22 & 1.68 & 1.18 \\
\hline 30 & 1.50 & 1.81 & 1.19 \\
\hline
\end{tabular}

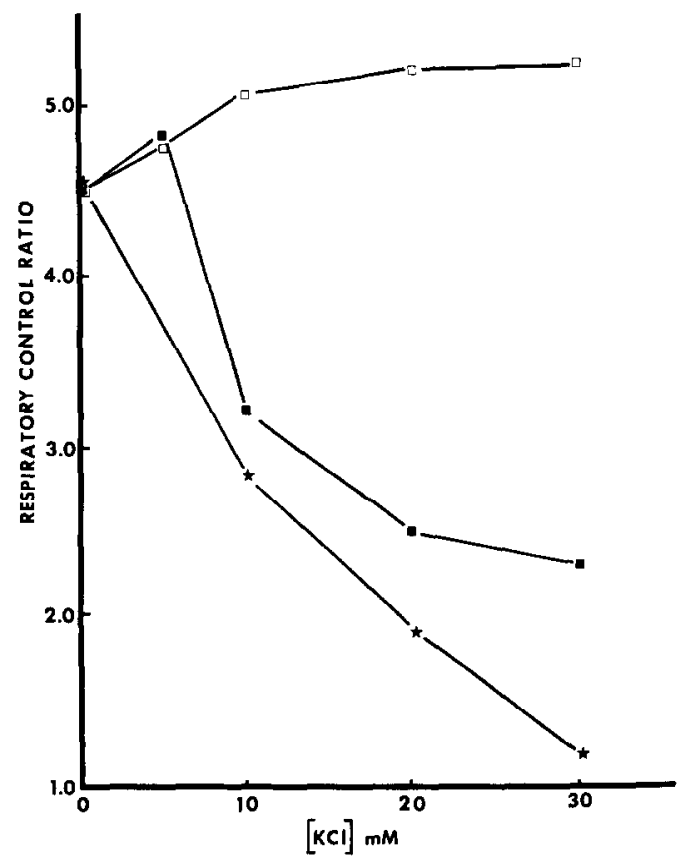

Fig. 2. The effect of valinomycin and potassium on respiratory control ratios of HBHM. Experimental conditions were the same as those described in Fig. 1. A mixture of pyruvate and malate was used as substrate. No valinomycin $(\square), 4 \mu \mathrm{g} / \mathrm{gm}$ protein valinomycin ( $\square$ ), $8 \mu \mathrm{g}$ valinomycin/gm protein $(\star)$. 
TABLE II

Effect of KCl and Valinomycin on State-3 and State-4 Respirition of HBHM

Experimental conditions were the same as those described for Fig. 1. Rates of respiration are reported as muatoms oxygen $/$ minute/mg mitochondrial protein.

\begin{tabular}{|c|c|c|c|c|c|c|}
\hline \multirow{3}{*}{$\mathrm{K}^{+}(\mathrm{m} \mathrm{M})$} & \multicolumn{6}{|c|}{ Valinomycin concentration } \\
\hline & \multicolumn{2}{|c|}{ - } & \multicolumn{2}{|c|}{$4 \mu \mathrm{g} / \mathrm{gm}$ protein } & \multicolumn{2}{|c|}{$8 \mu \mathrm{g} / \mathrm{gm}$ protein } \\
\hline & State 3 & State 4 & State 3 & State 4 & State 3 & State 4 \\
\hline 0 & 280 & 62 & 247 & 55 & 247 & 54 \\
\hline 5 & 240 & 50 & 254 & 53 & 264 & 72 \\
\hline 10 & 238 & 47 & 254 & 79 & 233 & 120 \\
\hline 20 & 213 & 41 & 245 & 112 & 241 & 144 \\
\hline 30 & 213 & 41 & 220 & 144 & 209 & 201 \\
\hline$\%$ change, $0-30 \mathrm{~mm} \mathrm{~K}^{+}$ & -24 & -34 & -11 & +262 & -15 & +372 \\
\hline
\end{tabular}

mycin a small increase in respiratory control was observed occasionally. In no case was there a significant decrease in the respiratory control ratio as a result of increased potassium in the absence of valinomycin, either in fresh mitochondria or in those incubated at $37^{\circ}$ for 15 minutes. In the presence of either 4 or $8 \mu \mathrm{g}$ of valinomycin per gram of mitochondrial protein, a profound decrease in the respiratory control ratio was consistently seen, coincident with an increase in the concentration of potassium in the medium. The higher concentration of valinomycin was more effective in decreasing the respiratory control ratio than was the lower valinomycin concentration. The same experiment was performed using five different preparations of HBHM preincubated at $37^{\circ}$ for 15 minutes. Similar qualitative results were obtained, but the magnitude of the response was smaller since the initial respiratory control ratio was considerably lower in preincubated HBHM. These data on both fresh and preincubated HBHM indicate that the limiting mitochondrial membrane in HBHM is essentially impermeable to potassium. In addition, the data reported in Figs. 1 and 2 and Table I on the effect of valinomycin in the absence of potassium support the contention of Moore and Pressman (3) that valinomycin is not an effective uncoupler of oxidative phosphorylation in the absence of potassium.

Table II shows the effect of valinomycin and potassium on state- 3 and state- 4 respira- tion (11). State-3 respiration, occurring in the presence of excess exogenous ADP, represents the maximal rate of electron transfer under phosphorylating conditions. State-4 respiration occurs when exogenous ADP is exhausted as a result of phosphorylation during state- 3 . The rate of respiration during state- 4 is a reflection of the steady state level of ADP provided by the turnover of ATP, as well as a reflection of the degree of coupling between the electron transfer and energy-conserving reactions. The addition of potassium to HBHM depressed the rate of state- 3 respiration to $76 \%$ of the control (no potassium) level, and the same conditions, but in the presence of valinomycin, resulted in a smaller depression of the state- 3 respiration (Table II). Potassium alone did not increase the controlled state- 4 respiration; but with 4 and $8 \mu \mathrm{g}$ of valinomycin per gram of mitochondrial protein, the rates of state- 4 respiration were increased by 262 and $372 \%$, respectively, in the presence of $30 \mathrm{~mm}$ potassium. These data clearly indicate that valinomycin facilitates the action of potassium on the mitochondrial system, and that valinomycin is required for the accelerating effect of the potassium on electron transfer during the controlled state-4. When identical experiments were performed on $\mathrm{HBHM}$ preincubated for 15 minutes at. $37^{\circ}$, no effect of potassium on state- 3 respiration was noted either in the absence or presence of valinomycin. In addition, potassium did not affect the rate of state- 4 


\section{TABLE III}

Effect of Potassium and Valinomycin on the Rate of Phosphorylation by HBHM

Assay procedure as described under Fig. 1. The phosphorylation rate is reported in terms of m $\mu$ moles of ADP phosphorylated/minute $/ 1.5 \mathrm{mg}$ HBHM protein. Substrate was pyruvate-malate.

\begin{tabular}{cccc}
\hline \multirow{2}{*}{$\mathrm{K}^{+}(\mathrm{mM})$} & \multicolumn{3}{c}{$\mu \mathrm{g}$ valinomycin/gm protein } \\
\cline { 2 - 4 } & 0 & 4 & 8 \\
\hline 0 & 910 & 844 & 845 \\
5 & 846 & 846 & 725 \\
10 & 805 & 656 & 424 \\
20 & 767 & 450 & 424 \\
30 & 735 & 309 & - \\
\hline
\end{tabular}

respiration when valinomycin was not present. Potassium did increase state-4 respiration in the presence of $4 \mu \mathrm{g}$ of valinomycin per gram of protein to approximately $200 \%$ of the initial value (with valinomycin, no potassium), and to approximately $400 \%$ of the control value with $8 \mu \mathrm{g}$ valinomycin per HBHM protein.

Höfer and Pressman (5) have reported that potassium, in the presence of valinomycin, increases the rate at which $\mathrm{ADP}$ is phosphorylated to ATP by rat liver mitochondria oxidizing glutamate. It was therefore of interest to calculate the rate of phosphorylation of ADP by HBHM in the presence of several concentrations of potassium and valinomycin (Table III). In the absence of valinomycin, increasing concentrations of potassium decreased the phosphorylation rate slightly. Both concentrations of valinomycin employed in this experiment resulted in an amplification of the decrease in the rate of phosphorylation in the presence of increasing potassium. These data are consistent with the valinomycin-potassium induced decrease in $\mathrm{ADP} / \mathrm{O}$ and respiratory control ratios reported above, and the increase in state- 4 respiration reported in Table II.

An attempt was made to gain information on whether potassium causes its effects on the mitochondrial reactions studied in these experiments by direct interaction with intermediates of oxidative phosphorylation, or indirectly by the utilization of energy from oxidative phosphorylation by way of an energy-requiring potassium transport system. Experiments were performed on the effect of potassium and valinomycin on the efficiency of ATP synthesis ( $\mathrm{P} / \mathrm{O}$ ratio) catalyzed by phosphorylating submitochondrial particles prepared from HBHM. The rational for this approach followed from the suggestion of Ernster (13) that "sonic" submitochondrial particles have their protruding repeating units, presumably the site of the phosphorylating enzymes (14), directed outward, and thus in direct contact with the surrounding medium. This is in contrast to the intact mitochondrion, which contains at least two membrane systems through which exogenous molecules must pass before coming into contact with the phosphorylating mechanism. It was hypothesized that potassium in the medium might compete with ATP formation, if the valinomycin-induced potassium effect on phosphorylation reactions was due to a direct interaction of potassium with an energized intermediate of oxidative phosphorylation. This in turn would lower the observed efficiency of oxidative phosphorylation in submitochondrial particles prepared in the absence of potassium. The addition

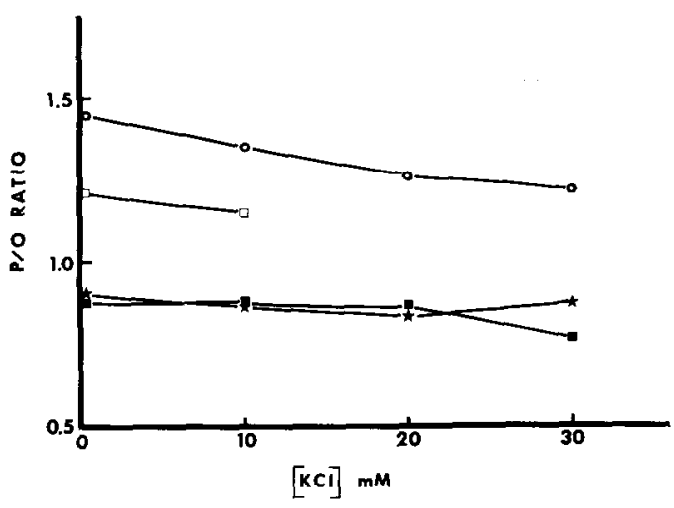

FIG. 3. The effect of valinomycin and potassium on $\mathrm{P} / \mathrm{O}$ ratios of ETPH$\left(\mathrm{Mg}^{++}, \mathrm{Mn}^{++}\right)$. Assay conditions as described in section on Materials AND Methods. NADH generated by alcohol:NAD oxidoreductase (EC 1.1.1.1), ethanol, and NAD. $\mathrm{NADH}$, no valinomycin (O); $\mathrm{NADH}, 4 \mu \mathrm{g}$ valinomycin/gm ETPH protein ( $\square$ ); succinate, no valinomycin ( $\star$ ); succinate, $4 \mu \mathrm{g}$ valinomycin/ gm ETPH protein ( $\square$. The ETPH $\left(\mathrm{Mg}^{++}, \mathrm{Mn}^{++}\right)$ preparation employed in this experiment was prepared with $20 \mathrm{kc}$ sound for 15 seconds. 
of several concentrations of potassium be tween 10 and $30 \mathrm{~mm}$ was essentially without effect when succinate was the substrate, but resulted in a slight decrease in the $\mathrm{P} / \mathrm{O}$ ratio of $\mathrm{EPTH}\left(\mathrm{Mg}^{++}, \mathrm{Mn}^{++}\right)$with generated $\mathrm{NADH}$ as substrate (Fig. 3). In the presence of $4 \mu \mathrm{g}$ of valinomycin per gram of ETPH protein, potassium caused a slight lowering of the $\mathrm{P} / \mathrm{O}$ ratio with $\mathrm{NADH}$ as substrate. There was no such effect with succinate as substrate except in the presence of $30 \mathrm{~mm}$ potassium, when a slight decrease of the $\mathrm{P} / \mathrm{O}$ ratio was noted. Potassiuminduced increases in $\mathrm{P} / \mathrm{O}$ ratios were never seen with submitochondrial particles with either substrate, and the decreases in $\mathrm{P} / \mathrm{O}$ ratios depicted in Fig. 3 were the most severe observed.

\section{DISCUSSION}

The purpose of this investigation was to study the action of potassium on oxidative phosphorylation catalyzed by beef heart mitochondria and by derived submitochondrial particles, in order to ascertain whether such actions were due to direct interaction with components of the oxidative phosphorylation system, or due to indirect interaction via a potassium transport system utilizing energy-derived from oxidative phosphorylation. Conflicting reports have appeared in the literature concerning the effects of potassium on mitochondrial reactions. Several investigators $(1,5,6,15,16)$ have suggested that potassium may be required for reactions involved in the phosphorylation process in intact mitochondria. For example, Pressman and Lardy (1) concluded that potassium participates in transphorylation reactions of oxidative phosphorylation catalyzed by liver mitochondria. Marcus and Manery (15) have also proposed that potassium has a direct effect on the phosphorylative process in intact pigeon muscle mitochondria. Their enclusion was based on increased $\mathrm{P} / \mathrm{O}$ ratios and rates of phosphorylation with increasing potassium concentrations. Such increases of $\mathrm{P} / \mathrm{O}$ ratios have not been observed by other investigators $(5,17)$. Ozawa et al. (18) have suggested recently that potassium ions exert a direct stimulatory effect on the electron transport system of mitochondria. Moore and Pressman (3) and Pressman (4) have provided direct evidence that valinomycin stimulates the active transport of potassium in mitochondria, but support for the potassium stimulation of ATP synthesis is considerably less direct (5). Höfer and Pressman (5) have proposed a mechanism for the stimulation of oxidative phosphorylation by valinomycin and potassium based on the known effects of valinomycin on mitochondrial ion transport, whereby an energized intermediate of oxidative phosphorylation may support the endergonic reactions of ATP synthesis or a "carrier system" for ion translocation into the mitochondrion. These authors visualize a local build-up of potassium at the site of a "potasssium-dependent energy-transfer reaction, thus stimulating ATP synthesis," and they conclude that potassium is required for ATP synthesis. This concept is supported by the data of Pressman and Lardy (1) whereby potassium-depleted liver mitochondria require potassium ions, but not sodium ions, to restore phosphorylation. The data derived from experiments on intact HBHM presented in the present paper would appear to be consistent with the concept of an energized intermediate of oxidative phosphorylation being shared by an ion carrier system and ATP synthesis. The increase in state-4 respiration in the presence of potassium and valinomycin as well as the decrease in the $\mathrm{ADP} / \mathrm{O}$ ratio and the rate of phosphorylation under the same conditions of potassium and valinomycin all point to a competition between ATP synthesis and potassium translocation for such an intermediate. However, the essential lack of effect of potassium in the absence and presence of valinomycin on $\mathrm{P} / \mathrm{O}$ ratios catalyzed by submitochondrial particles strongly indicates that potassium does not interact directly with such an intermediate, unless the activated intermediate of oxidative phosphorylation is postulated to be contained in a compartment of the submitochondrial particle no longer available to potassium ions. At least two alternative explanations for the data on submitochondrial particles are possible. Either the energy-requiring ion transport 
carrier is located on the outer membrane of the mitochondrion and is thus no longer present in ETPH preparations, or the ion transport system is located on the inner mitochondrial membranes but is a vectoral transport. In the latter case, potassium ions would have to find an entry into the inner space of the ETPH in order to be actively transported in an outward direction, since it is quite likely that the orientation of the ETPH membrane is the reverse of that in the intact mitochondrion $(13,14)$. It is not possible at this time to make a definitive choice between these alternate explanations.

\section{ACKNOWLEDGMENTS}

We are grateful to Miss Cornelia Woermann for skilled technical assistance and to Dr. B. C. Press. man for a generous supply of valinomycin.

\section{REFERENCES}

1. Pressman, B. C., and Lardy, H. A., Bio. chim. Biophys. Acta 18, 482 (1955).

2. OpIt, L. J., ANd Cirarnock, J. S., Biochim. Biophys. Acta 110, 9 (1965).

3. Moore, C., and Pressman, B. C., Biochem. Biophys. Res. Commun. 15, 562 (1964).

4. Pressman, B. C., Proc. Natl. Acad. Sci. U.S. 53, 1076 (1965).

5. Hörer, M., And Pregsman, B. C., Biochemistry 5, 3919 (1966).
6. Cockrell, R. S., Harris, E. J., and Pressman, B. C., Biochemistry 5, 2326 (1966).

7. Löw, H., and Vallin, I., Biochim. Biophys. Acta 69, 361 (1963).

8. Hansen, M., And Smith, A. L., Biochim. Biophys. Acta 81, 214 (1964).

9. BeYer, R. E., in "Methods in Enzymology," Vol. 10 ("Oxidation and Phosphorylation"; R. W. Estabrook and M. E. Pullman, eds.), p. 519. Academic Press, New York (1967).

10. Gornall, A. G., Bardawill, C. J., AND David, M. M., J. Biol. Chem. 177, 751 (1949).

11. Chance, B., and Williams, G. R., Advan. Enzymol. 17, 65 (1956).

12. Christie, G. S., Ahmed, K., McLean, A. E. M., AND Judah, J. D., Biochim. Biophys. Acta 94, 432 (1965).

13. Ernster, L., Federation Proc. 24, 1222 (1965).

14. Racker, E., Tyler, D. D., Estabrook, R. W., Conover, T. E., Parsons, D. F., and Chance, B., in "Oxidases and Related Redox Systems" (T. E. King, H. S. Mason, and M. Morrison, eds.), p. 1077. Wiley, New York (1965).

15. Marcus, G. J., and Manery, J. F., Canad. J. Biochem. 44, 1127 (1966).

16. Marcus, G. J., Manery, J. F., and Dryden, E. F., Canad. J. Biochem. 44, 1133 (1966).

17. Geiger, E., ANd MeLchior, N., personal communication.

18. Ozawa, K., Seta, K., Araki, H., and Handa, H., J. Biochem. 61, 352 (1967). 